\title{
Synthesis of Polythiophene Derivatives and Their Application for Electrochemical DNA Sensor
}

\author{
Seung Ku KANG, ${ }^{1}$ Ji-Heung KIM, ${ }^{2}$ Jeongho AN, ${ }^{1}$ Eun Kyu LEE, ${ }^{3}$ Junhoe CHA, ${ }^{4}$ \\ Geunbae LIM, ${ }^{4}$ Yong Soon PARK, ${ }^{5}$ and Dong June CHUNG ${ }^{1, \dagger}$ \\ ${ }^{1}$ Department of Polymer Science and Engineering, Sungkyunkwan University, Suwon, 440-746, Korea \\ ${ }^{2}$ Department of Chemical Engineering, Sungkyunkwan University, Suwon, 440-746, Korea \\ ${ }^{3}$ Department of Chemical Engineering, Hanyang University, Ansan, 425-791, Korea \\ ${ }^{4}$ Biochip Project Team, MEMS Lab., Samsung Advanced Institute of Technology, P.O. Box 111, Suwon, Korea \\ ${ }^{5}$ Department of Medical Information Engineering, Kwangju Health College, Kwangju, 506-701, Korea
}

(Received June 10, 2004; Accepted September 24, 2004; Published December 15, 2004)

\begin{abstract}
In this study, we synthesized thiophene derivatives by the protection of the carboxyl group of 3-thiophene acetic acid(monomer) with different substituted benzyl groups for hybridized electrochemical DNA sensors composed of a conductive polymer and oligo-DNA (ODN). In general, while 3-thiophene acetic acid is not suitable for direct electro-polymerization because of the electron withdrawing effect of the $-\mathrm{COOH}$ group in above monomer, our synthesized thiophene monomer derivatives are easily electro-oxidized to form stable electro-active polymer films by the protection of $-\mathrm{COOH}$ group. These polymer films showed the specific electrochemical characteristics of poly 3-alkylthiophenes with a reversible redox transition in the range of $0.8-1.6 \mathrm{~V}$ in $\mathrm{CV}$ (cyclic voltammogram) measurement. Biological recognition was monitored by comparison with the $\mathrm{CV}$ signal from the hybridization of single and double strands of ODN. The oxidation current of double strand ODN was less than that of the single strand, which corresponds to a decrease in electrochemical activity of the conducting polymer with an increase in stiffness of the side group of the electroactive polymer. [DOI 10.1295/polymj.36.937]

KEY WORDS Biosensor / DNA Chip / Electrochemical Polymerization / Conductive Polymer / Polythiophene /
\end{abstract}

In recent years, some studies on biosensors used for monitoring and diagnostic tests of disease from transmigration, virus, and bacterial infections have focused on the detection of unique signals from body components such as blood-corpuscles, blood plasma, tissue cells, and metabolites. Particularly, there has been concentrated interest in the development of sequential detection methods by electrochemical sensors due to the potential for fabricating small and economical sensing chips. ${ }^{1}$ For the detection of an electrochemical signal, it is essential to measure different electrical signals from a conducting polymer with recognition molecules immobilized on electroactive films before and after hybridization with target molecules. Until recently, when fabricating biosensors through active biomolecules such as DNA and enzymes, such biomolecules were entrapped (rather than directly bonded) onto a conducting polymer. ${ }^{2,3}$ Recently, however, the novel tool of immobilization for active biomolecules on a synthesized conducting polymer surface through covalent bond has been reported. ${ }^{4,5}$ On the basis of these previous studies, our devices were fabricated through three stages, monomer modification, electro-polymerization, and oligo-DNA immobilization. First, for electro-polymerization of a monomer containing a functional group on electrode, the functional group on the monomer must be protected by an activating agent (pentafluoro phenol, 4-chlorobenzyl alcohol and $N$-hydroxy phthalimide), because nucleophilic attack by monomeric functional groups such as hydroxyl $(-\mathrm{OH})$ and carboxyl $(-\mathrm{COOH})$ to radical cations of monomeric intermediate inhibit the electro polymerization reaction. ${ }^{6,7}$ Therefore, protecting and deprotecting the functional group is required in second step for direct electro polymerization. ${ }^{8}$ In third step, after electro-polymerization, an active biomolecule (oligo-DNA) for target molecule recognition is immobilized on the conductive polymer surfaces.

We also investigated biological recognition precursor behavior by the electrochemical signal change evaluation originating from hybridization of the probe oligonucleotide and the target molecule.

\section{EXPERIMENT}

\section{Materials}

3-Thiophene acetic acid, pentafluorophenol, 4chlorobenzyl alcohol, $N$-hydroxyphthalimide, $N, N^{\prime}-$ dicyclohexylcarbodiimide (DCC), ferrocenyl acid $(\mathrm{FeCOOH})$, acetonitrile (99.8\% anhydrous) and di-

${ }^{\dagger}$ To whom correspondence should be addressed (Tel: 82-31-290-7286, Fax: 82-31-292-8790, E-mail: djchung@ @kku.edu). 

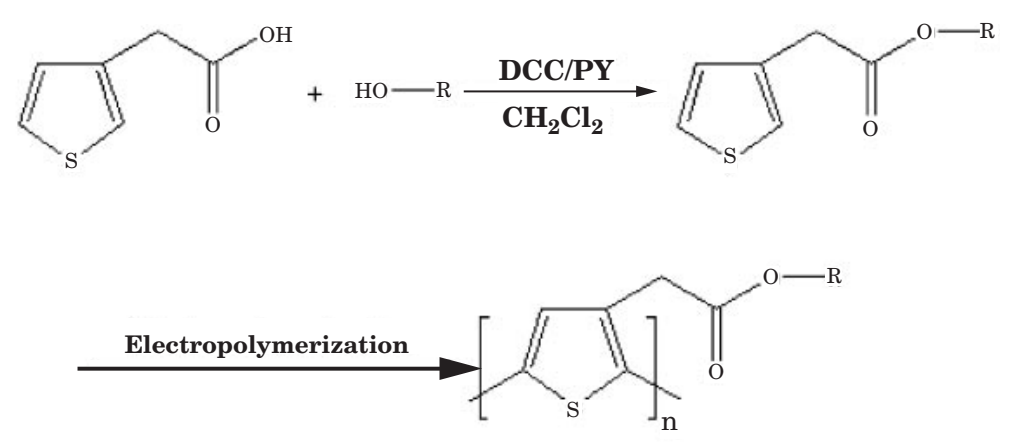

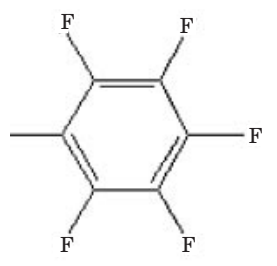

Pentafluorophenol

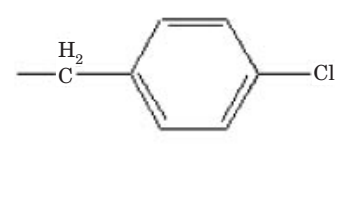

4-chlorobenzylalcohol

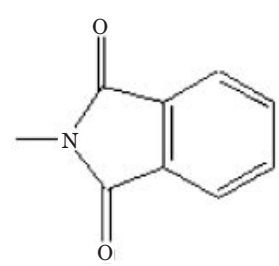

N-hydroxy phthalimide

Scheme 1. Synthesis of thiophene derivatives with different protecting groups and their electro polymerization.

methyl sulfoxide (DMSO) were purchased from Aldrich Chem. Co. (Milwaukee, USA). Electrochemical grade tetrabutylammonium hexafluorophosphate $\left(\mathrm{TBAPF}_{6}\right)$ was purchased from Fluka Chim. Gmbh. (Buchs, Switzerland). Protease free phosphate buffer ( $\mathrm{pH}$ 7.4), DNase, RNase and sodium chloride were purchased from Sigma Chemical Co. (St. Louis, USA). Target ODNs and amino-modified oligonucleotide (probe-ODN; 5'- $\mathrm{NH}_{2}-\left(\mathrm{CH}_{2}\right)_{6}-(\mathrm{GTTCTTCTCAT}-$ CATC)-3') were purchased from Genotech Co., Ltd. (Taejeon, Korea). All chemicals were used without any purification.

To characterize the conducting polymer films, potentiostat (EG\&G 273A, Gaithersburg, USA), FT IR (Mattson 5000, Wisconsin, USA) and ${ }^{1} \mathrm{H} /{ }^{13} \mathrm{C}$ NMR (Varian Unity Inova, 500MH, Germany) measurements were performed.

\section{Modification of the Monomers}

The thiophene derivatives were synthesized by reaction of 3-thiophene acetic acid with three kinds of benzyl alcohols using DCC as a coupling reagent according to Scheme $1 .{ }^{9}$ A reaction mixture of 3-thiophene acetic acid (10 mmole), benzyl alcohols (10 mmole) and pyridine ( 20 mmole) was stirred with a magnetic bar in $50 \mathrm{~mL}$ methylene chloride (MC) for $20 \mathrm{~min}$. Excess DCC was then added at $0^{\circ} \mathrm{C}$. After the reaction, the reaction mixture was kept for $20 \mathrm{~h}$ at the same temperature. The product was filtered for elimination of $N, N^{\prime}$-dicyclohexylcarbourea (DCU, by product) and the filtrate was washed with $4 \% \mathrm{HCl}$, $8 \% \mathrm{NaHCO}_{3}$, and distilled water several times respectively, and then dehydrated using $\mathrm{MgSO}_{4}$. After the

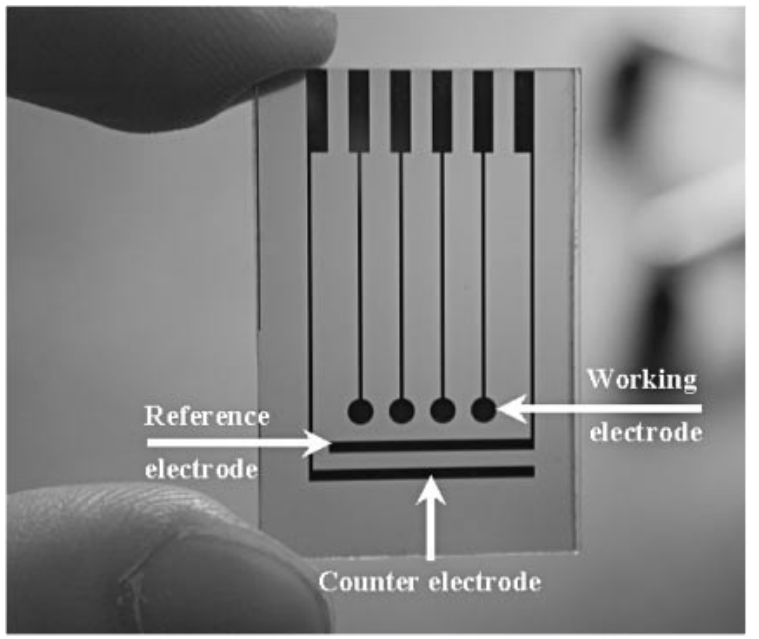

Figure 1. Photograph of Pt chip electrode.

solvent removal under reduced pressure, the monomer was purified by a silicagel column chromatogram using an MC or MC/Hexane mixture for eluent.

\section{Preparation of Chip Electrodes}

Pt was used for working, counter, and internal pseudo-reference electrode material on a chip (Figure 1). ${ }^{10}$ The area of the working electrode was $2 \mathrm{~mm}^{2}$ and that of the counter and reference electrodes was $8 \mathrm{~mm}^{2}$ respectively. The distance between the working and reference electrode was $1 \mathrm{~mm}$. The overall glass chip size was $2 \times 3 \mathrm{~cm}$ in width and length. The Pt reference electrode was calibrated with an $\mathrm{Ag} / \mathrm{AgCl}$ standard reference electrode in $0.1 \mathrm{M}$ acetonitrile/FeCOOH mixed solution. 

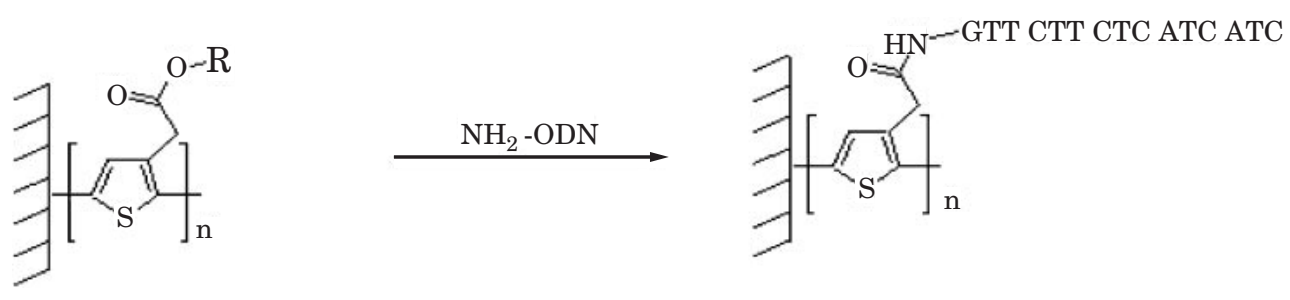

Scheme 2. Modification of polythiophene film surface with probe-ODN.

\section{Electro-polymerization}

The polymer films were prepared in the Pt coated glass chip described above by electro polymerization. ${ }^{11}$ The Pt chip was pre-cleaned in piranha solution $\left(\mathrm{H}_{2} \mathrm{O}_{2} / \mathrm{H}_{2} \mathrm{SO}_{4}, 1 / 3\right.$ in volume) for $10 \mathrm{~min}$ to remove organic impurities, rinsed with distilled water several times, and dried in air. The reaction medium of electro polymerization was prepared from synthesized monomer $(0.1 \mathrm{~mol} / \mathrm{L})$ and $\mathrm{TBAPF}_{6}(0.1 \mathrm{~mol} / \mathrm{L})$ in acetonitrile as an electrolyte. During polymerization, the monomers were electro-polymerized by the three electrode system under a potential range of $0-1.7 \mathrm{~V}$ (vs. Pt electrode) and a scanning rate of $50 \mathrm{mV} / \mathrm{s}$ at one cycle. After polymerization, the modified chip was rinsed with acetonitrile and then electro activities were assessed in a monomer free electrolyte solution. In this case, a potential range of $0-1.2 \mathrm{~V}(\mathrm{vs} . \mathrm{Pt})$ and scan rate of $50 \mathrm{mV} / \mathrm{s}$ were applied.

\section{Removal of Protecting Group and Oligo DNA Immo- bilization on Film Surface}

Scheme 2 showed simultaneous chemical reactions for removal of the protecting group on the polymer film in the chip and introduction of ODN to the same polymer film. A coupling reaction between $-\mathrm{NH}_{2}$ in ODN and $-\mathrm{COOH}$ in polymer film occurred in a sodium bicarbonate buffer solution ( $\mathrm{pH}$ 9.6) containing a small amount of DMSO for $1 \mathrm{~d}$ at room temperature. After the coupling reaction, the DNA immobilized chip was rinsed with same buffer several times.

\section{Hybridization of Target DNA}

The target complementary was 3'-(CAAGAAGAGTAGTAG)-5'. The solution including the target molecule $(0.2 \mathrm{mmol} / \mathrm{L})$ was prepared with a phosphate buffer solution ( $\mathrm{pH}$ 7.4) containing $1 \mathrm{M} \mathrm{NaCl}$. Hybridization with the target ODN was performed in a hybridization chamber at $37^{\circ} \mathrm{C}$ for $1 \mathrm{~h}$ by simple dropping of the target ODN solution on a working electrode immobilized with probe ODN.

\section{Measurement of Chips before and after Hybridiza- tion of Target $O D N$}

For a comparison of the oxidation current of a single strand (probe ODN only) and a double strand (probe and target ODN) DNA on a hybrid chip, the change of CV current was measured before and after hybridization of the target ODN. First, the Pt chip was rinsed in acetonitrile several times to remove unbinded target ODN. The reaction medium of the $\mathrm{CV}$ measurement was prepared from $\mathrm{TBAPF}_{6}(0.1 \mathrm{~mol} /$ L) in acetonitrile as an electrolyte (monomer free electrolyte solution). For measurement, the hybridized chip was monitored by the three electrode system under a potential range of $0-1.2 \mathrm{~V}(v s$. Pt electrode) and a scanning rate of $50 \mathrm{mV} / \mathrm{s}$ per cycle.

\section{RESULTS AND DISCUSSION}

\section{Chemical Modification of the Monomers}

FT IR spectroscopy clearly revealed that all modified monomers showed disappearance of the $-\mathrm{OH}$ peak at $3200-3600 \mathrm{~cm}^{-1}$ originating from the $-\mathrm{COOH}$ group in the original monomers and also showed two new characteristic ester peaks at 1736 and $1751 \mathrm{~cm}^{-1}$ from the $\mathrm{R}-\mathrm{COO}-\mathrm{R}^{\prime}$ group in the modified monomers. These were well defined $\mathrm{C}=\mathrm{O}$ stretch peaks in the range of $1735-1750 \mathrm{~cm}^{-1}$ of normal esters instead of a $\mathrm{C}=\mathrm{O}$ stretch in the range of $1700-1710 \mathrm{~cm}^{-1}$ arising from normal carboxyl acid in the original monomer.

${ }^{1} \mathrm{H}$ NMR data of the modified monomers were as follows; in the case of pentafluorophenyl thiophene3-acetate $\left({ }^{1} \mathrm{H} \mathrm{NMR}\left(\mathrm{CDCl}_{3}\right)\right.$ : $7.42(\mathrm{~d}, 1 \mathrm{H},-\mathrm{SCHCH}-)$, 7.32 (s, 1H, -SCHC-), 7.14 (d, 1H, -SCHCH-) 4.05 (s, $\left.2 \mathrm{H},-\mathrm{CH}_{2} \mathrm{COO}-\right)$ ); for 4-chlorobenzyl thiophene3 -acetate $\left({ }^{1} \mathrm{H} \mathrm{NMR}\left(\mathrm{CDCl}_{3}\right): 7.32(\mathrm{~d}, 1 \mathrm{H},-\mathrm{SCHCH}-)\right.$, $7.17(\mathrm{~s}, 1 \mathrm{H},-\mathrm{SCHC}-), 7.03(\mathrm{~d}, 1 \mathrm{H},-\mathrm{SCH} \underline{\mathrm{CH}}-)$, 3.79 (s, $\left.2 \mathrm{H},-\mathrm{CH}_{2} \mathrm{COO}-\right), 5.15$ (s, $2 \mathrm{H},-\mathrm{COOC \textrm {CH } _ { 2 }}-$ ), 7.48 (d, 2H, benzyl), 7.38 (d, 2H, benzyl)); and for $\mathrm{N}$-hydroxyphthalimido thiophene-3-acetate $\left({ }^{1} \mathrm{H}\right.$ NMR $\left(\mathrm{CDCl}_{3}\right): 7.30(\mathrm{~d}, 1 \mathrm{H},-\mathrm{SCHCH}-), 7.29(\mathrm{~s}, 1 \mathrm{H}$, -SHC-), 7.05 (d, 1H, -SCHCH-), 3.98 (s, 2H, $\left.-\underline{\mathrm{CH}}_{2} \mathrm{COO}-\right), 7.89$ (d, 2H, benzyl), 7.79 (d, 2H, benzyl)).

CV Measurement during Electro-polymerization of Thiophene Derivatives

Synthesized monomers in Scheme 1 were polymerized on a Pt working electrode of a chip by electrical 

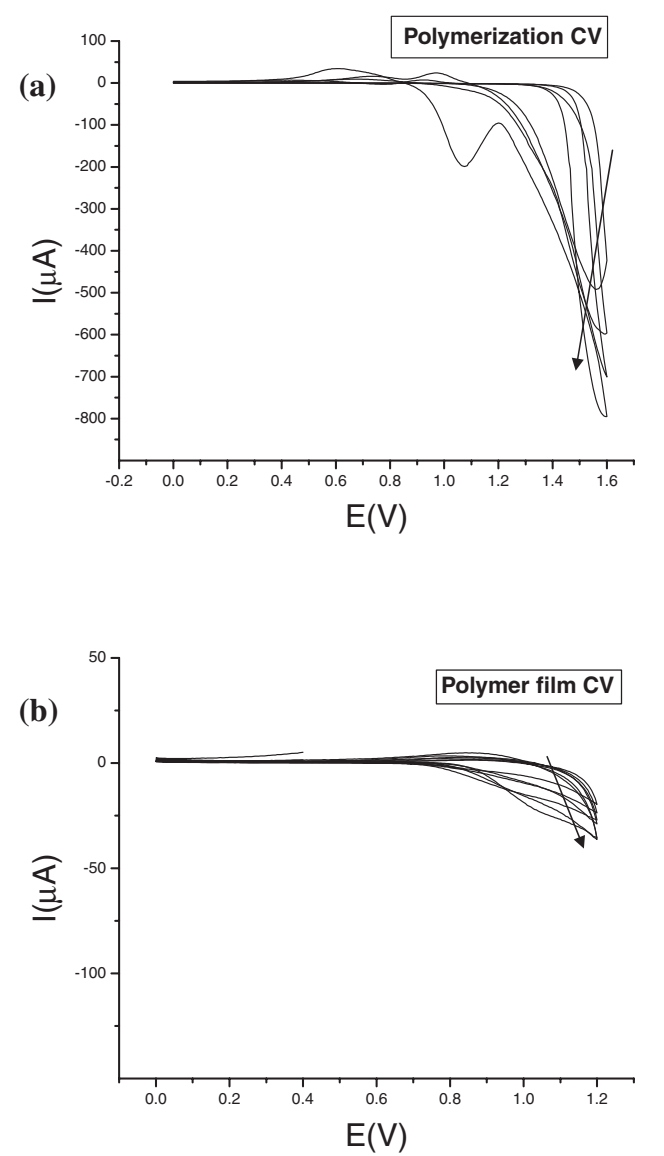

Figure 2. CV for pentafluorophenyl thiophene-3-acetate protecting film. (a) During polymerization, (b) After polymerization.

method. Figures $2 \mathrm{a}, 3 \mathrm{a}$, and $4 \mathrm{a}$ show the $\mathrm{CV}$ results of monomers measured during polymerization in acetonitrile solution containing $0.1 \mathrm{~mol} / \mathrm{L}$ of corresponding monomers and $\mathrm{TBAPF}_{6}$ (as electrolyte). In the first cycle of $\mathrm{CV}$, all monomers showed a sharp increase of current (owing to oxidation of monomer) in the $1.0-1.3 \mathrm{~V}$ region. Upon repeating scan cycles, the redox current was shifted to a specified range (such as $1.1-1.5 \mathrm{~V}$ ), indicating formation of electrical redox systems on the working electrode surface by the progress of polymerization. From the similarity of the CV curves of all monomers in Figures 2a, 3a, and 4a, we found out that the different protecting groups in monomers did not affect significant charge disturbance in thiophene polymerization process. ${ }^{12}$

\section{Measurement of Thiophene Polymer Films}

Figures $2 b, 3 b$, and $4 b$ show the $\mathrm{CV}$ measurement results of polymer films recorded in a previous acetonitrile solution (monomer free) containing $0.1 \mathrm{~mol} / \mathrm{L}$ $\mathrm{TBAPF}_{6}$ after polymerization. Figures $3 \mathrm{~b}$ and $4 \mathrm{~b}$ show typical redox curves of electro-active polythiophene derivatives. In the case of Figure $2 b$, upon consideration of the bulky property of the pentafluorophenol protecting group and the short spacer between the
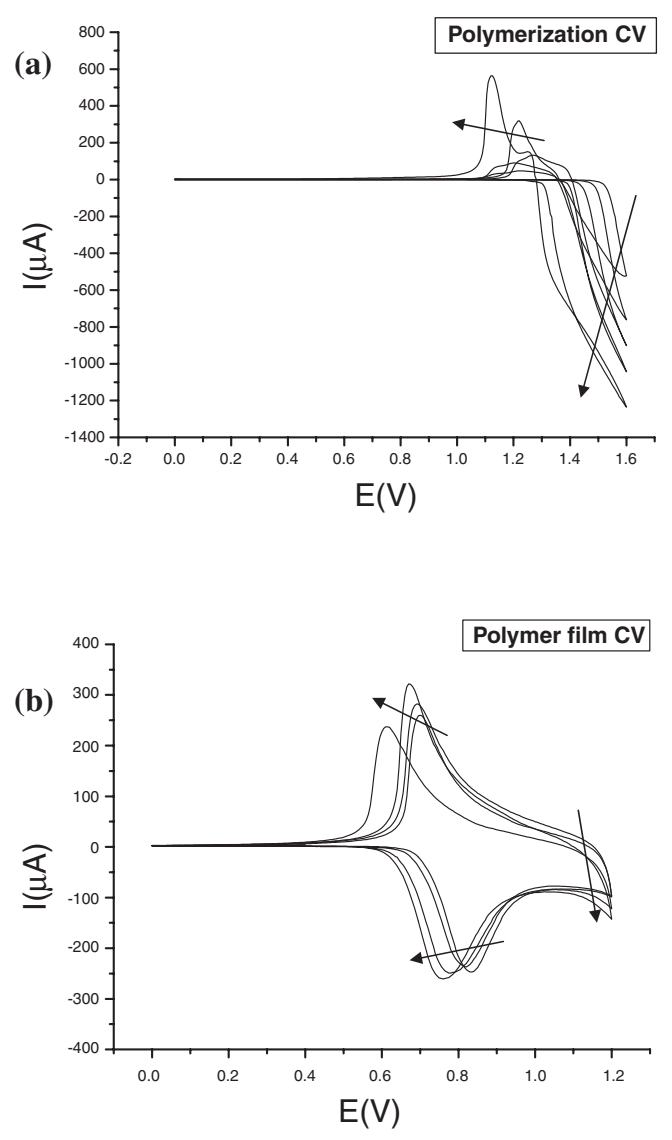

Figure 3. CV for 4-chlorobenzyl thiophene-3-acetate protecting film. (a) During polymerization, (b) After polymerization.

thiophene ring and the functional group, the CV curves in Figure $2 b$ indicate insufficient redox behavior. Such phenomenon was explained as follows; in the case of pentafluorophenol protecting, the new synthesized thiophene derivatives could not form a coplanar conjugated polythiophene backbone during the polymerization and caused torsion angle between the thiophene monomer units in the polymer chain, ${ }^{13}$ therefore this type of polymer did not show good electroactivity. And electrical conductivity was determined by two-probe apparatus using oxidized form of polymer films containing 4-chlorobenzyl and $\mathrm{N}$ hydroxypthalimido protecting group. This measurement gave a value in the rage of $10^{-5}$ to $10^{-4} \mathrm{~S} \mathrm{~cm}^{-1}$, indicating lower conductivity compared to that of normal polythiophene films.

\section{Immobilization of Probe-DNA}

As shown in Scheme 2, the protecting group was easily removed from the chip electrode and also allowed a direct substitution of its leaving group $(-\mathrm{O}-\mathrm{R})$ to a terminal amine group in probe ODN. The introduction of the ODN was confirmed by IR absorption peaks revealed at 695 and $790 \mathrm{~cm}^{-1}$ associated with the phosphordiester bond and at 1750 and $1650 \mathrm{~cm}^{-1}$ associated with a newly formed amide 

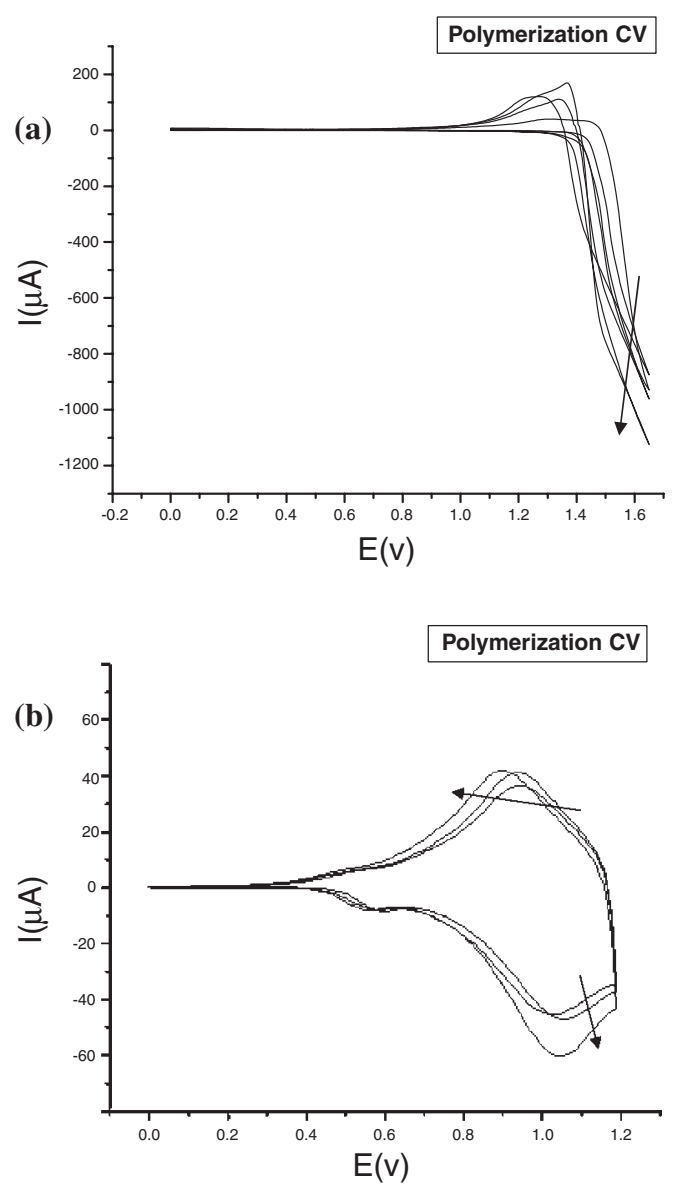

Figure 4. $\mathrm{CV}$ for $N$-hydroxyphthalimido thiophene-3-acetate protecting film. (a) During polymerization, (b) After polymerization.

bond between ODN hybrid and polythiophene. This immobilization method is simply compared to the general method because restoring the carboxyl group and immobilizing the probe material through a covalent bond can be done in single step. Therefore, two procedures (deprotecting and activating) can be eliminated in the chip fabrication process, which is advantageous in terms of fabrication reliability.

\section{Confirmation of Hybridization}

Figure 5 shows two different $\mathrm{CV}$ curves, one is obtained from a polythiophene film containing a covalently connected probe ODN and the other is obtained from a hybridized film containing probe and target ODN through incubation of previous polythiophene film and target ODN in the hybridization chamber. The decrease of intensity of the oxidation current of the single strand (probe-DNA in Figure 5, without target ODN) compared to the double strand (Hyd-DNA in Figure 5, with target ODN) in the CV curve can be explained by the formation of polar hydrogen bonds between the DNA bases $(\mathrm{G}, \mathrm{T}, \mathrm{A}, \mathrm{C})$ in probe and target ODN at the polymer surface. These hydro-
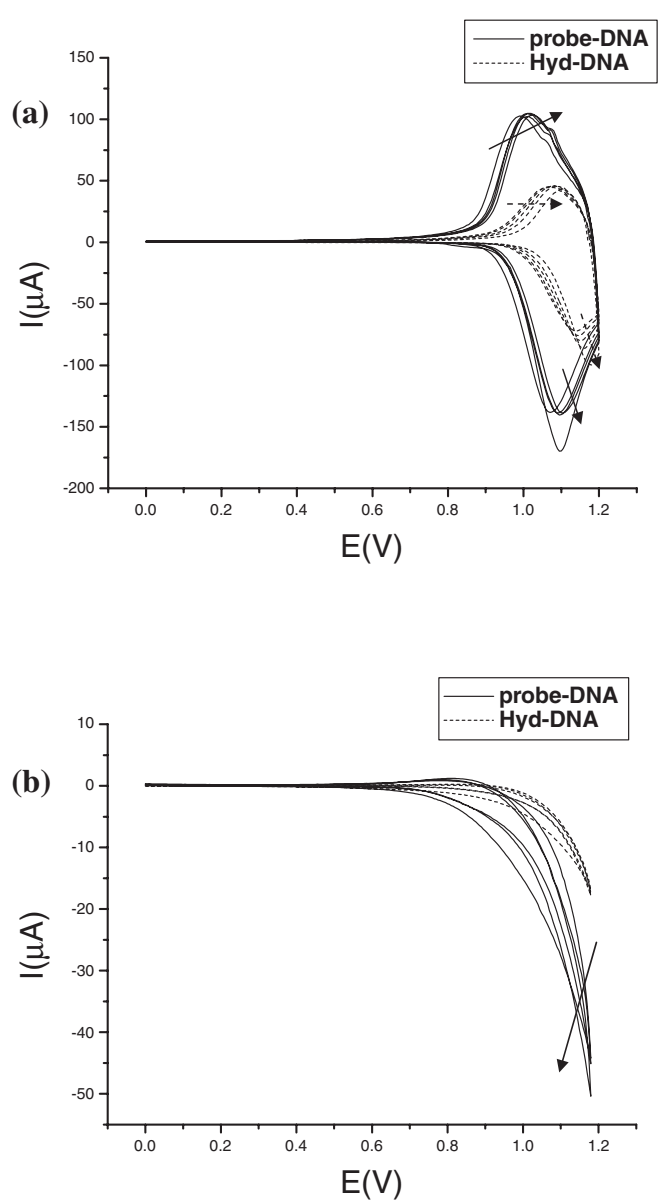

Figure 5. CV diagram after hybridization of probe-ODN and target-ODN. (a) 4-chlorobezyl thiophene-3-acetate protecting film, (b) $\mathrm{N}$-hydroxyphthalimido thiophene-3-acetate protecting film.

gen bonds form a potential barrier to the rotation of the polymer backbone and can suppress bulky conformational changes occurring along the conjugated polymer backbone. Therefore, as shown in HydDNA CV curve in Figure 5, the increase of bulkiness and stiffness of the pendant groups leads to a right shift of the oxidation potential in the conjugated polymer chain.

According to hybridization, the redox current intensity of the deposited conducting film was greatly changed according to the ratio of hybridization between probe and target ODN. Therefore we can convert the obtained electric signal on polythiophene film to the amount of hybridization of target ODN, can get very useful quantitative information about DNA sensing using conducting polymers. Hence this system has high potential as an effective sensing tool for DNA chips.

\section{CONCLUSIONS}

We synthesized novel thiophene derivatives for biosensors through electro-polymerization and could 
obtain electro-active conducting polymer films on a $\mathrm{Pt}$ chip electrode through protection of the carboxyl group of monomers (3-thiophene acetic acid) with different benzyl substituted groups. These protecting groups also had direct chemical substitution ability to the $-\mathrm{NH}_{2}$ group in probe ODN. We monitored molecular recognition by comparison with the electrochemical signal (cyclic voltammogram) of single and double strand ODNs. Modified films (containing probe ODN) on a Pt chip using thiophene derivatives could play an effective role as biological recognition precursors, and could be applied to bio-sensing systems including DNA chips. As further work, we will study the quantitative determination of the probeODN on the surface of film by EQCM and the regioregular chemical structure affecting sensitivities and physical characteristics of DNA chip.

Acknowledgment. This work was supported by a Grant-in-Aid for Next-Generation New Technology Development Programs from the Korea Ministry of Commerce, Industry and Energy (Project Name: Technology development for production of high-value proteins in transgenic plants and cultured plant cells (A18-06-04)).

\section{REFERENCES}

1. S. Cosnier, Biosens. Bioelectron., 14, 443 (1999).

2. a) J. Wang, X. Cai, G. Rivas, H. Shiraishi, P. A. M. Farias, and N. Dontha, Anal. Chem., 68, 2629 (1996).

b) J. Wang, G. Liu, M. R. Jan, and Q. Zhu, Electrochem. Commun., 5, 1000 (2003).

c) J. Wang, Anal. Chim. Acta, 500, 247 (2003). d) J. Wang, G. Liu, and A. Merkoçi, Anal. Chim. Acta, 482, 149 (2003).

3. a) G. Marrazza, I. Chianella, and M. Mascini, Biosens. Bioelectron., 14, 43 (1999).

b) K. Kerman, D. Ozkan, P. Kara, B. Meric, J. J. Gooding, and M. Ozsoz, Anal. Chim. Acta, 462, 39 (2002).

c) M. Zhao, D. B. Hibbert, and J. J. Gooding, Biosens. Bioelectron., 18, 827 (2003).

4. a) K. M. Millan and S. R. Mikkelsen, Anal. Chem., 65, 2317 (1993).

b) K. H. Row, Y. Polyakova, and S. K. Lee, Ind. Eng. Chem., 9, 473 (2003).

5. H. K.-Youssoufi, F. Garnier, P. Srivastava, P. Godillot, and A. Yassar, J. Am. Chem. Soc., 119, 7388 (1997).

6. a) P. Buerle, M. Hiller, S. Scheib, T. Msokolowski, and E. Umbach, Adv. Mater., 8, 214 (1996).

b) I. Mukoyama, K. Aoki, and J. Chen, J. Electroanal. Chem., 531, 133 (2002).

c) Y. Tezuka, K. Aoki, and T. Ishii, Electrochim. Acta, 44, 1871 (1999).

7. G. Li, G. Kobmehl, H. P. Welzel, G. Engelmann, W. D. Hunnius, W. Plieth, and H. Zhu, Marcromol. Chem. Phys., 199, 525 (1998).

8. R. L. Presdge, D. R. K. Harding, and W. S. Hancock, J. Org. Chem., 41, 2579 (1976).

9. P. Siebe, Helv. Chim. Acta, 60, 2711 (1977).

10. J. Cha, J. I. Han, Y. Choi, D. S. Yoon, K. W. Oh, and G. Lim, Biosens. Bioelectron., 18, 1241 (2003).

11. J. H. Lee, J. Y. Bae, and D. J. Chung, Polymer (Korea), 23, 129 (1999).

12. S. H. Jeong, J. Y. Bae, J. H. Kim, and D. J. Chung, Polymer (Korea), 26, 28 (2002).

13. G. Li, G. Kobmehl, H. P. Welzel, G. Engelmann, W. D. Hunnius, W. Plieth, and H. Zhu, Marcromol. Chem. Phys., 199, 2255 (1998). 